${ }^{1}$ Faculty of Medicine, Department of Dental Diseases and Dental Morphology, University of Ljubljana, Ljubljana, Slovenia ${ }^{2}$ Faculty of Medicine, Department of Paediatric and Preventive Dentistry, University of Ljubljana, Ljubljana, Slovenia

${ }^{3}$ Department of Operative Dentistry and Endodontics, University Medical Centre Ljubljana, Ljubljana, Slovenia

\section{Correspondence to} Dr Tomaž Hitij, tomazhitij@gmail.com

Accepted 2 January 2017
CrossMark

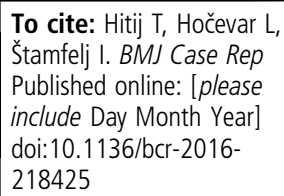

\title{
Bilateral presence of radix entomolaris in first and second permanent mandibular molars identified in a Caucasian woman
}

\author{
Tomaž Hitij, ${ }^{1}$ Luka Hočevar, ${ }^{2}$ Iztok Štamfelj ${ }^{1,3}$
}

\section{DESCRIPTION}

A healthy Caucasian girl aged 12 years was referred to the dental clinic by a general dentist who failed to completely instrument canals in the mesial and distal root of tooth 36 (FDI system). In the first session, supernumerary root radix entomolaris (RE)

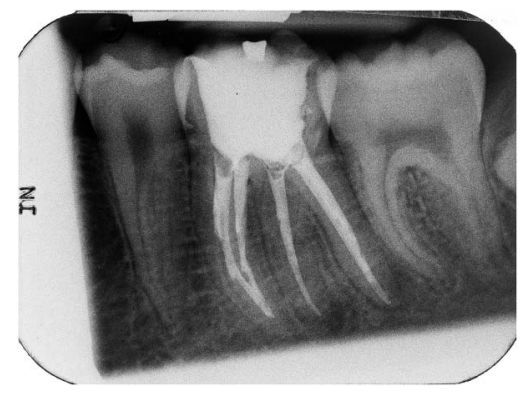

Figure 1 Postoperative radiograph of the left first permanent mandibular molar exposed with mesial horizontal angulation. The tooth was obturated by cold lateral condensation technique using precurved stainless steel spreaders, precurved gutta-percha cones and $\mathrm{AH}$ Plus sealer (Dentsply DeTrey).
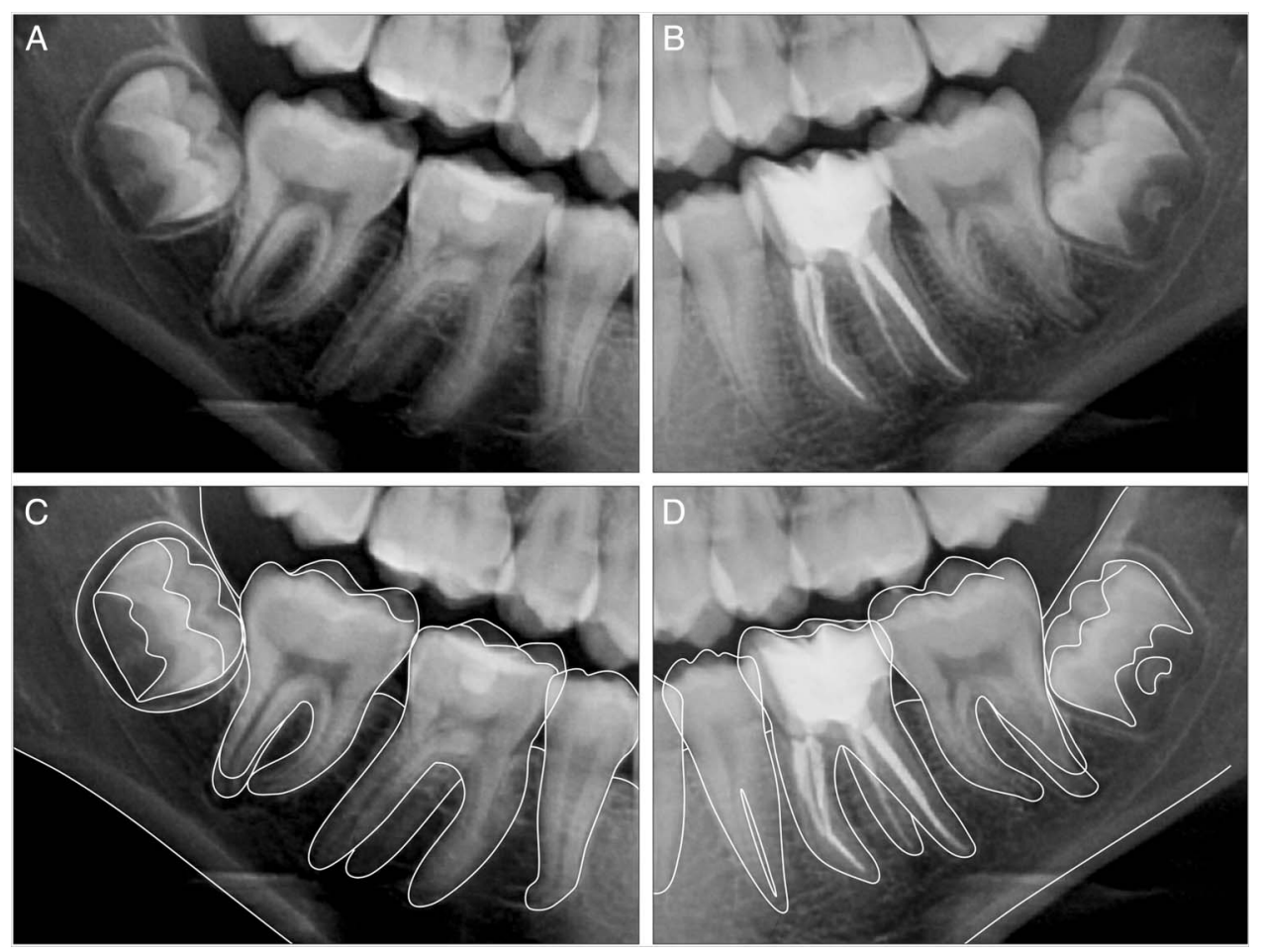

Figure 3 An enlarged lower right (A) and left (B) side of the panoramic radiograph indicating bilateral presence of $\mathrm{RE}$ on first and second permanent molars. Outlines of teeth are marked on images $C$ and $D$, which correspond to images $A$ and $B$, respectively. was identified and cone beam CT (CBCT) scan was taken. Afterwards, several ledges in the root canals were successfully negotiated and treatment was completed in the third session (figure 1). CBCT revealed the presence of $\mathrm{RE}$ also on tooth 37 and

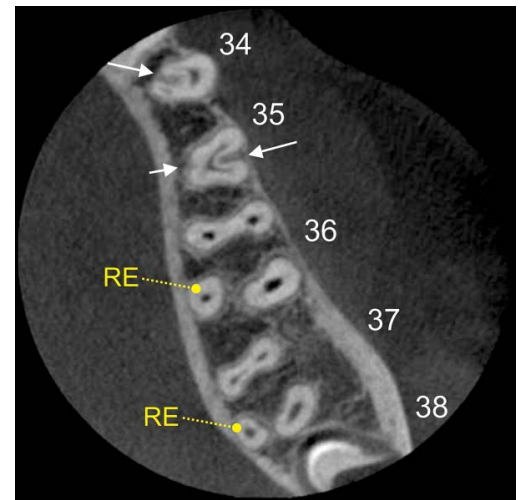

Figure 2 Axial $\mathrm{CBCT}$ image of the roots showing radix entomolaris (RE) on the left first and second permanent mandibular molar. Deep grooves $(\rightarrow)$ and C-shaped canal pattern are seen on the first and second premolar. Teeth are numbered according to the FDI system.

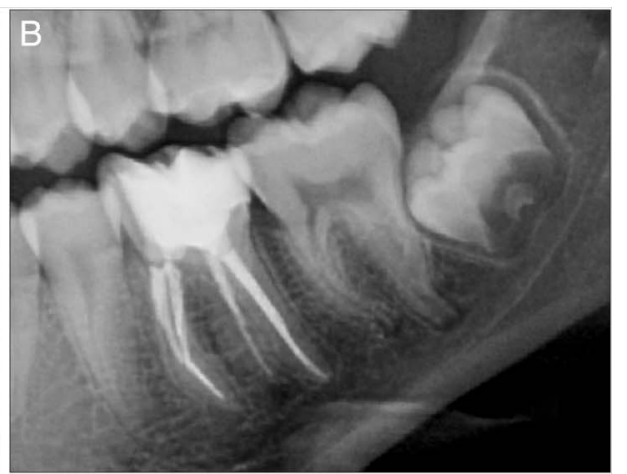



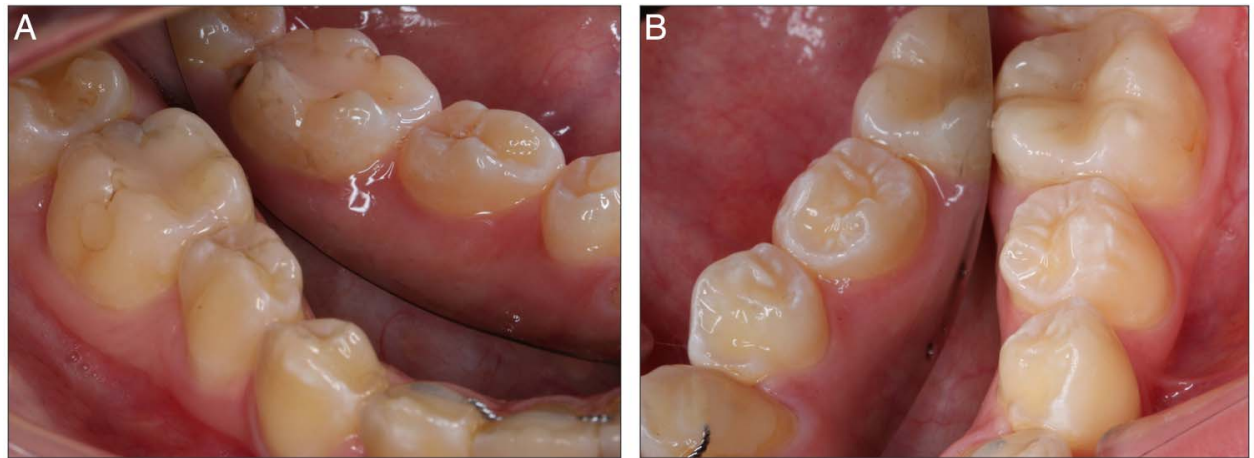

Figure 4 Unusual coronal morphology of right (A) and left (B) mandibular second premolar. Mirror images on both pictures show teeth from the lingual side.

deep longitudinal grooves and C-shaped canal pattern in roots of both neighbouring premolars (figure 2). Additionally, panoramic radiograph indicated the presence of RE on the contralateral first and second molars (figure 3). Roots of mandibular third molars have not yet been developed. Clinically, the crowns of both mandibular second premolars were mesiodistally enlarged; the right one exhibiting four cusps and the left one exaggerated marginal ridges (figure 4).

Individuals with bilateral $\mathrm{RE}$ on first and second mandibular molars are extremely rare, especially in ethnic Europeans who have a low prevalence of this radicular trait. Unilateral presence of $\mathrm{RE}$ in both aforementioned teeth has been documented in

\section{Learning points}

- If a clinician identifies a mandibular molar with radix entomolaris, he or she should thoroughly evaluate all available radiographic images of neighbouring as well as contralateral molars and premolars.

- Unusual coronal morphology should always alert the clinician to the possibility of unusual radicular morphology.

- CBCT is useful for appreciation of extremely complex root canal systems, such as those of teeth with supernumerary roots. two endodontic patients of Chinese $^{1}$ and Indian descent ${ }^{2}$ however, researchers failed to mention this in text. In another Indian patient, right first and left second mandibular molars were affected. ${ }^{3}$ Development of RE and a tendency of mandibular premolars to increase the root number may be associated. ${ }^{4}$ Observations also indicate that in mandibular premolars, atypical coronal enlargements may be accompanied by increased differentiation of the root. ${ }^{5}$

Contributors $\mathrm{TH}$ and $\mathrm{LH}$ examined and treated the patient. $\mathrm{TH}, \mathrm{LH}$ and IS contributed equally to the preparation of the manuscript.

Competing interests None declared.

Patient consent Obtained.

Provenance and peer review Not commissioned; externally peer reviewed.

\section{REFERENCES}

1 Tian J, Liang G, Qi W, et al. Odontogenic cutaneous sinus tract associated with a mandibular second molar having a rare distolingual root: a case report. Head Face Med 2015;11:13.

2 Banode AM, Gade V, Patil S, et al. Endodontic management of mandibular first molar with seven canals using cone-beam computed tomography. Contemp Clin Dent 2016;7:255-7.

3 Poorni S, Senthilkumar A, Indira R. Radix entomolaris in mandibular molars confirmed using spiral CT: a case report. ENDO 2010;4:55-9.

4 Kovacs I. A systematic description of dental roots. In: Dahlberg A, ed. Dental morphology and evolution. Chicago: The University of Chicago Press, 1971:211-56.

5 Schulze C. Anomalien und Mißbildungen der menschlichen Zähne. Berlin: Quintessenz Verlags, 1987:105-28.

Copyright 2017 BMJ Publishing Group. All rights reserved. For permission to reuse any of this content visit

http://group.bmj.com/group/rights-licensing/permissions.

BMJ Case Report Fellows may re-use this article for personal use and teaching without any further permission.

Become a Fellow of BMJ Case Reports today and you can:

- Submit as many cases as you like

- Enjoy fast sympathetic peer review and rapid publication of accepted articles

- Access all the published articles

- Re-use any of the published material for personal use and teaching without further permission

For information on Institutional Fellowships contact consortiasales@bmjgroup.com

Visit casereports.bmj.com for more articles like this and to become a Fellow 